\title{
Gender differences in the association between theory of mind, empathy and conduct disorder: A cross-sectional study
}

\author{
Olber Eduardo Arango-Tobón a*, Gabriel David Pinilla Monsalve ${ }^{\mathrm{b}}$, Antonio Olivera-La Rosa ${ }^{a}$, \\ Silvia Juliana Orejarena Serrano ${ }^{c}$, César Andrés Carmona Cardona ${ }^{a}$
}

\author{
a Universidad Católica Luis Amigó, Medellín, Colombia \\ ${ }^{b}$ Fundación Valle del Lili - Universidad Icesi, Cali, Colombia \\ c Universidad Industrial de Santander (UIS), Bucaramanga, Colombia
}

Received 22 October 2019; accepted 2 April 2020

\author{
KEYWORDS \\ Adolescence, \\ gender differences, \\ empathy, \\ theory of mind, \\ conduct disorder
}

\begin{abstract}
The purpose of this research was to explore gender differences regarding theory of mind and empathy abilities in a sample of adolescents with conduct disorder $(n=46$; males=28 and females=18). Empathy (cognitive and emotional dimensions) and theory of mind (reading the mind through the eyes) were tested based on an observational method with a crosssectional design. Statistical analysis included: description of variables according to their type, assessment of quantitative correlations and logistic multivariate modelling for identifying variables that differentiate female from male patients. The results demonstrated significant gender differences in empathy and theory of mind evaluations. Particularly, women showed different scores for cognitive/emotional empathy and in the Reading the Mind through the Eyes test, with a lower number of behavioural symptoms. The results are discussed in light of the current empirical evidence, and some future directions in the study of conduct disorder are suggested.

(c) 2020 Fundación Universitaria Konrad Lorenz. This is an open access article under the CC BYNC-ND license (http://creativecommons.org/licenses/bync-nd/4.0/).
\end{abstract}

Diferencias de género en la asociación entre teoría de la mente, empatía y trastorno de conducta: Un estudio transversal

Resumen El objetivo de este estudio fue explorar las diferencias de género en habilidades de teoría de la mente y empatía en una muestra de adolescentes con trastorno de conducta ( $n=46 ; 28$ hombres y 18 mujeres). Se determinó un abordaje observacional con un diseño de corte transversal mediante el cual se evaluó la empatía (dimensiones cognitiva y afectiva) y teoría de la mente (lectura de la mirada). El análisis estadístico incluyó la descripción de las variables de acuerdo con su naturaleza, la evaluación de correlaciones cuantitativas, y el diseño de un modelo logístico multivariado para identificar las variables que diferencian los pacientes según su género. Los resultados indicaron diferencias significativas por género tanto en empatía como en teoría de la mente. Las mujeres presentaron de manera consistente
PALABRAS CLAVE

Adolescencia, diferencias sexuales, empatía, teoría de la mente, trastorno de conducta

\footnotetext{
* Autor para correspondencia.

Correo electrónico: olber.arangoto@amigo.edu.co
}

https://doi.org/10.14349/sumapsi.2020.v27.n1.5

ISSN 0121-4381, ISSN-E 2145-9797/@ 2020 Fundación Universitaria Konrad Lorenz. Este es un artículo Open Access bajo la licencia CC BY-NCND (http://creativecommons.org/licenses/by-nc-nd/4.0/). 
diferencias en los niveles de empatía cognitiva/afectiva y test de la mirada, con un menor número de síntomas de conducta. Los resultados se discuten a la luz de la evidencia empírica actual y se sugieren algunas direcciones futuras en el estudio del trastorno de conducta.

(c) 2020 Fundación Universitaria Konrad Lorenz. Este es un artículo Open Access bajo la licencia CC BY-NC-ND (http://creativecommons.org/licenses/bync-nd/4.0/).

Conduct disorder is characterized by a behavioural pattern where the patient breaks the rules and violates the rights of others. Children and adolescents with this disorder present behaviours related to aggressions, destruction of private property, theft, trickery and serious violation of rules. It has been established that the prevalence of the disorder is higher in men than in women (American Psychiatric Association, 2013).

According to the gender, some studies have identified differences in clinical criteria related to the disease prevalence, semiological characteristics, developmental patterns or evolution of the disorder (Berkout, Young \& Gross, 2011; Keenan, Wroblewski, Hipwell, Loeber, \& Stouthamer-Loeber, 2010). For example, McEachern and Snyder (2012) suggest that clinical differences in conduct disorder between genders can be found more often in the type of delinquency and aggressions. It is also considered that men have a higher tendency for physical aggression, while in women relational aggressions are more common, including behaviours oriented towards affecting relationships through rumour propagation in order to damage the social status of their victims (American Psychiatric Association, 2013; Arango et al., 2018; Holl, Kirsch, Rohlf, Krahé \& Elsner, 2018; Olweus, 1999).

In spite of the acknowledgement of deficiencies in empathic, emotional and social cognition processes as important predictors of antisocial behaviour during childhood and adolescence, there is little evidence about gender differences that involve tasks related to theory of mind and empathy abilities (Arango, Montoya, Puerta \& Sánchez, 2014; Baker, 2009; Eisenberg \& Eggum, 2009; Fairchild, Stobbe, Goozen, Calder \& Goodyer, 2010; Peets, Hodges, \& Samivalli, 2010; Ibanez, Huepe, Gempp, Gutiérrez, \& Rivera-Rei, 2013). The latter justifies that this study is focused on the examination of empathic processes and theory of mind in adolescents with conduct disorder.

The concept of "theory of mind" was used by the primatologists Premack and Woodruff (1978) to describe the skills for interpreting human behaviour in a mental sphere, in other words, the abilities of a person to infer and make assumptions regarding other people's emotions, feelings, affections, thoughts and intentions, and in turn, to act and influence their behaviour depending on these assumptions. According to Warnell and Redcay (2019), depending on the perspective to evaluate the theory of mind skills (task complexity, affective content or implicit or explicit responses) and population groups by age (pre-schoolers, children or adults), the results of said measurement will produce highly variable and poorly related data. Based on the above, this study assumes that ToM is a multidimensional process, but only one dimension will be evaluated from the perspective of affective content that reflects the recognition of emotional states from an adolescent's point of view.

Deficiencies in social cognition in general, and particularly in theory of mind, would cause difficulties when "reading" the emotions of others, understanding their intentions in an inferred and contextualized way, and emotionally and adaptively connecting with the social environment (Arango et al, 2014; Ellis, 1982; Marshall \& Marshall, 2011; Sharp, 2000; 2006, 2008; Sharp, Croudance, \& Goodyer, 2007).

On the other hand, empathy is defined as a response linked to emotional and cognitive processes and involves the ability to understand other people's emotional states (Eisenberg, Fabes \& Spinrad, 2006). This response generates willingness in the individual to comprehend and internalize other people's emotions and feeling. An empathic person has the ability to assume feelings and to interpret the way in which other subjects emotionally value situations and respond to distress and needs. Empathy is also defined from a cognitive dimension, which involves more complex mental processes, providing the individual with the ability to understand feelings in specific situations. This perspective is closely related to theory of mind since it involves the ability to read and place ourselves in another person's mental and emotional position (perspective taking) (Davis, 1996; Stavrinides, Georgiou, \& Theofanous, 2010).

In the literature, some researchers have explained the factors associated with disruptive behaviour patterns in both genders. In this context, an important aspect is the consideration that women are less likely to present serious transgressional behaviours when compared to men, since they tend to be more empathic. According to Broidy, Cauffman, Espelage, Mazerolle and Piquero (2003), the rates of transgression in men are significantly higher than in women, both in adolescence and adulthood. Therefore, it could be suggested that empathic differences between men and women moderate behaviours associated with conduct disorder (Arango et al., 2018; Deschamps, Schutter, Renemans, \& Matthys, 2014).

Broidy et al., (2003), analysed the relationship between empathy and delinquency in adolescents of both genders. The study results indicate that in the group of delinquents, men scored lower in terms of behavioural empathy than women. Regarding emotional empathy, there were not significant differences between genders. In contrast, after comparing the delinquent adolescents' group with control subjects, differences were found for both behavioural and emotional empathy.

Both empathy and the abilities to attribute mental states to ourselves and others are the main components of social cognition. Moreover, gender differences regarding these abilities have been identified. Walker (2005), observed that boys with disruptive behaviours had better abilities in cognitive empathy, whereas girls exhibited better performance in theory of mind tasks and higher levels of emotional empathy and were more likely to express behaviours and feelings oriented towards helping others. Gender and age were identified as significant moderators in relationships between empathy, theory of mind and disruptive behaviours. 
In this sense, Kokkinos, Voulgaridou, Mandrali and Parousidou (2016) analysed the strength of the relationship between theory of mind, relational aggressions and moral disengagement using gender as a moderator variable in a sample of pre-adolescents. Authors determined that boys with deficiencies in theory of mind abilities were more likely to morally disengage from their actions, thus becoming involved and participating in aggressions. Furthermore, girls with the same deficiencies were less likely to morally disengage, which led them to become less involved in aggressive behaviours.

However, evidence about the impact of gender in theory of mind and empathy abilities in relation to aggressive and antisocial behaviour shows mixed results. Theory of mind and empathy play an important role in conduct disorder; nonetheless, this role has not been deeply studied. Some data suggest there are no gender differences in the correlation between theory of mind and aggressive behaviour and that the main discrepancies are found in the type of aggressions performed by each gender. Nevertheless, evidence does not explain if this is a result of social cognition profiles (Holl et al., 2018).

In this context, the purpose of this study was to investigate gender differences in theory of mind and empathy abilities in a sample of adolescents with conduct disorder. Our main hypotheses suggest that gender plays an important role in both the existence of disorder symptoms and the level of cognitive/emotional empathy and theory of mind processes. Specifically, we consider that women present less behavioural symptoms since they have better abilities in emotional empathy and theory of mind.

\section{METHOD}

\section{Participants}

The sample for this study was obtained from a more extensive project called "Theory of mind and empathy as predictors of antisocial behaviours in adolescence". Participation in this study was voluntary, and both adolescents and their parents or legal tutors provided informed consent. The Institutional Review Board/Ethical Committee from Universidad Católica Luis Amigó also granted its approval. Sampling was probabilistic and stratified according to the institutions that care for offenders and the schools endorsed by the Capuchin Tertiary Congregation, which are present in different Colombian cities (Bogotá, Medellin, Manizales and Tunja); 239 adolescents were selected - 157 adolescents with conduct disorder CD and 82 control individuals. The decision whether or not to include cases depended on the fulfilment of criteria for conduct disorder. In order to exclude patients with psychosis, autism, neurological diseases or any medical or genetic condition that might suggest the existence of another developmental or behavioural disorder, clinical histories of all participants were reviewed.

For the present study, all female adolescents in the CD group were selected $(n=18)$, while the inclusion of 28 male adolescents was carried out randomly from the general database. No additional exclusion criterion was considered. Taking into account the statistical methods and results extracted from the Sharp (2008) and Ackermann et al., (2019) studies, an alternative hypothesis $\left(\mathrm{H}_{1}\right)$ is proposed for determining the presence of a difference in score averages $\geq 3$ points among men and women for the direct and indirect measures of cognitive/emotional empathy, and a priori expected standard deviations of \pm 3 for both genders. Sample size calculation for comparing two means was performed in OpenEpi, (The OpenEpi Project, Georgia USA), pointing out that at least 43 subjects ( 26 females and 17 males) are required when defining a $97.5 \%$ confidence interval with a power of $80 \%$, and assuming an minimum allocation rate by gender of $1.5: 1$ supported by the higher prevalence of conduct disorder in males (Fairchild \& Smaragdi, 2018). A difference-of-two-means hypothesis is proposed because this is the central tendency measure reported by the aforementioned authors; nonetheless, statistical analysis in this paper is conditioned to sampling distribution of the data.

\section{Instruments}

\section{Clinical diagnosis}

Initially, the Diagnostic and Statistical Manual of Mental Disorders (DSM IV-TR) was used to determine the participant's diagnostic condition. The number of symptoms and diagnosis confirmation was established using the conduct disorder unit of the MINI International Neuropsychiatric Interview, MINI Kid (Sheehan et al. 1997). It consists of a short diagnostic interview exploring the main psychiatric disorders from Axis I of the DMS IV and the ICD-10. Some validity and reliability studies have compared the MINI with the SCID-P for the DSM III-R and the CIDI (a structured interview developed by the World Health Organization for non-clinical interviewers for ICD-10). The results of these studies prove that MINI Kid has an acceptably high score of validity and reliability. However, it can be managed in a shorter time (from 11.6 to 18.7 minutes, with an average of 15 minutes) than other instruments. For this study, the MINI-Kid 5.0.0 version adapted to Colombian Spanish was used (Sheehan, Shytle, Milo, Lecrubier \& Jergueta, 2006).

\section{Intellectual functioning}

To establish the intelligence quotient, the Kaufman Brief Intelligence Test (K-BIT) (Kaufman \& Kaufman, 1997) was employed. It is a general intelligence measure for children, adolescents and adults comprising a wide age range (from 4 to 90 years old). The evaluation is carried out individually and takes approximately 30 minutes. It consists of two subtests: vocabulary and matrices. Scores obtained through this test have a mean of $100(S D=15)$, both for subtests of vocabulary and matrices, and composite IQ. This study used the Spanish adaptation of Cordero and Calonge (Kaufman \& Kaufman, 1997).

\section{Empathy}

The Interpersonal Reactivity Index (Davis, 1980) is a tool used to measure empathy. This is a self-report instrument consisting of 28 items which are divided into four subscales with seven items each. They measure four different dimensions from the overall concept of cognitive/emotional empathy. The four subscales are: perspective taking, fantasy, empathic concern, and personal distress. Davis (1980) states that internal consistency of these subscales ranges from 
0.68 to 0.79 , and the test-retest reliability ranges from 0.61 to 0.81 during an interval of $60-75$ days. Construct validity of these subscales was confirmed through correlations with other empathy measures (Davis, 1983). This study used the Spanish adaptation of Pérez, Paúl, Etxeberría, Montes and Torres (2003).

\section{Theory of mind}

"Reading the Mind in the Eyes" (Baron-Cohen, Wheelwright, Hill, Raste, \& Plumb, 2001) is a test where 36 photographs of eye regions of different people are shown to participants one at a time in an established order. The eyes represent complex mental states. Baron-Cohen et al. (2001) affirm that mental states involve the attribution of a belief or intention to a person. For each stimulus, there are four words describing emotions and the participant must choose which one best expresses what the person in the photograph is thinking or feeling. Each correct response is worth one point. The maximum score is 36 . This study used the Spanish adaptation of Rueda, Cabello and Fernández-Berrocal (2013).

\section{Procedure}

The evaluation team included clinical psychologists from the Research Group in Basic and Applied Neurosciences at the Universidad Católica Luis Amigó. First, DSM IV-TR criteria for conduct disorder were applied. Then, the MINI-Kid was employed to establish the fulfilment of the criteria for conduct disorder according to gender. Finally, empathy and theory of mind tests were applied to the selected sub-sample. Each evaluation took approximately one hour and a half in a single session that was carried out in quiet, comfortable and peaceful places.

\section{Statistical Analyses}

Quantitative variables were reported with means and standard deviations, or medians and interquartile ranges, according to the distribution identified with Shapiro-Wilk test. Likewise, absolute frequencies and percentages were reported for categorical features. Considering the sampling distribution of variables, statistically significant differences between both genders were analysed based on Student's $t$-test and Mann-Whitney $U$ test. Size effect after parametric tests was assessed using Cohen's $d$ and 95\% confidence intervals; similarly, a non-parametric effect size punctual estimator was also calculated based on $U$ statistics. Regarding qualitative information, contingency tables were defined and analysed through Chi-square test and Fisher's exact test, depending on the number of individuals per cell. Moreover, correlation coefficients were calculated using Spearman's method as this technique seems robust for evaluating non-normal data in small samples. $p$ values under 0.05 (95\% significance level) was selected as the cut-off for statistical relevant findings.

Afterwards, a logistic bivariate regression was applied on each characteristic defining gender as the dependent variable. Those with a $p$ value less than 0.20 were selected to construct a final multivariate model with the objective of determining a set of distinctive features associated with female gender among adolescents with conduct disorder. Since the intelligence quotient can be measured in two different ways (quantitatively discrete or qualitatively ordinal), and there is the possibility of including each Interpersonal Reactivity Index subscale versus calculating the median score for each empathy dimension, multiple logistic regressions were calculated. The stepwise backward methodology was implemented for variable selection.

The final model was chosen according to the number of independent variables (maximum 3-4 features according to the sample size to guarantee $B$ coefficients stability) and its application for neuropsychological evaluation in terms of simplicity and accuracy. Finally, goodness of fit, model's specification and residuals were evaluated by means of linktest, Pearson and Hosmer-Lemeshow tests. Statistical analysis was carried out in Stata v.13.0. (StataCorp, Texas USA).

\section{RESULTS}

In general, $39.1 \%$ of the sample were women. They presented a fewer number of behavioural symptoms $(d=1.163)$ and a higher score in the Reading the Mind in the Eyes test $(d=1.529)$. Women also showed better results in empathic dimensions like perspective taking $(d=1.420,95 \% \mathrm{Cl} 0.761$ 2.079), empathic concern $(d=1.367)$ and personal distress $(d=1.133)$. Female adolescents obtained a higher score both in the cognitive $(d=0.916,95 \% \mathrm{Cl} 0.295-1.537)$ and emotional components $(d=1.604)$ when grouping subscales according to the studied empathy dimension (see Table 1).

There was a significant inverse correlation between number of symptoms and emotional empathy score $(\rho=[-.375], p=.010)$, but not for the cognitive dimension $(\rho=.047, p=.756)$. Within the emotional empathy, empathic concern $(\rho=[-.411], p=.005)$ exhibited a stronger correlation than personal distress $(\rho=[-.245], p=.101)$. Additionally, correlations of approved years of schooling and age with intelligence quotient was analysed, but no significant results were found $(\rho<.200, p>.050)$.

Consistent results with the above analysis can be observed from logistic regressions. The association between female gender and the number of behavioural symptoms $(95 \% \mathrm{Cl} 0.02-0.50)$, the score in the Reading the Mind in the Eyes test $(95 \% \mathrm{Cl} 1.15-1.80)$, cognitive empathy $(95 \% \mathrm{Cl}$ 1.07-1.67) and emotional empathy $(95 \% \mathrm{Cl} 1.12-2.14)$ was reaffirmed (see Table 2).

During the construction of the multivariate models, it was demonstrated that including the intelligence quotient as a quantitative or qualitative variable was irrelevant for the final model. Likewise, preference of empathy dimensions over subscales individual scores lead to obtain a model with a slightly higher goodness of fit (pseudo $\mathrm{R}^{2}=66.05 \%$ vs. $59.26 \%$ ). The first model was based on subscale scores and included the number of behavioural symptoms (OR 0.03; 95\% $\mathrm{Cl} 0.00-5.22$ ) and perspective taking (OR 1.61; $95 \% \mathrm{Cl}$ 1.14-2.95). In addition to the difference in multivariate adjustment, the regression included a non-significant constant $(p=.066)$ after the stepwise backward. Alternatively, the model obtained through dimensions is based on the score of the Reading the Mind in the Eyes test $(95 \% \mathrm{Cl} 1.15$ 2.63) and emotional empathy $(95 \% \mathrm{Cl} 1.12-4.11)$ (see Table 3$).$ 
Table 1 Bivariate analysis for variables of interest depending on gender. Quantitative variables are described by means and standard deviations, or medians and interquartile ranges, according to their distribution.

\begin{tabular}{|c|c|c|c|}
\hline Variables & Women $(n=18)$ & Men $(n=28)$ & $p$ value \\
\hline Age in years & $17(16-17)$ & $17(16-17)$ & .282 \\
\hline \multicolumn{4}{|l|}{ Education } \\
\hline Elementary (1-5) & $22.22 \%(n=4)$ & $14.29 \%(n=4)$ & \multirow{3}{*}{.241} \\
\hline Basic Secondary (5-8) & $61.11 \%(n=11)$ & $46.43 \%(n=13)$ & \\
\hline High School (9-11) & $16.67 \%(n=3)$ & $39.29 \%(n=11)$ & \\
\hline Approved years & $6.889 \pm 1.711$ & $7.321 \pm 2.42$ & .482 \\
\hline \multicolumn{4}{|l|}{ Socioeconomic status (strata) } \\
\hline 1 & $94.44 \%(n=17)$ & $89.29 \%(n=25)$ & \multirow{2}{*}{.999} \\
\hline 2 & $5.56 \%(n=1)$ & $10.71 \%(n=3)$ & \\
\hline Behavioural symptoms & $7(6-8)$ & $8(8-8)$ & $<.001$ \\
\hline Intelligence quotient (IQ) & $84.61 \pm 15.95$ & $91.29 \pm 17.3$ & .188 \\
\hline Vocabulary & $86.61 \pm 16.06$ & $91.93 \pm 15.64$ & .276 \\
\hline Matrices & $89(77-101)$ & $96(79.5-111)$ & .246 \\
\hline IQ $>90$ points & $27.78 \%(n=5)$ & $57.14 \%(n=16)$ & .072 \\
\hline Reading the Mind in the Eyes test & $22.5(20-27.5)$ & $16(13.25-18)$ & $<.001$ \\
\hline Cognitive empathy & $19.81 \pm 3.561$ & $16.84 \pm 3.016$ & .006 \\
\hline Perspective taking & $20.06 \pm 4.556$ & $14.64 \pm 3.257$ & $<.001$ \\
\hline Fantasy & $19.56 \pm 3.222$ & $19.04 \pm 4.834$ & .664 \\
\hline Emotional empathy & $22.5(20.5-27.63)$ & $18(16.13-20.38)$ & $<.001$ \\
\hline Empathic concern & $25.5(22.75-30.25)$ & $20.5(18-23.75)$ & $<.001$ \\
\hline Personal distress & $21(16-23.5)$ & $16(13-18)$ & .001 \\
\hline
\end{tabular}

Table 2 Odds ratios of potential factors associated with female gender in adolescents with conduct disorder.

\begin{tabular}{|c|c|c|}
\hline Variables & OR & Pseudo $\mathbf{R}^{2}$ \\
\hline Age in years & $.55(0.21-1.38)$ & $2.69 \%$ \\
\hline \multicolumn{3}{|l|}{ Education } \\
\hline Elementary (1-5) & Reference & Reference \\
\hline Basic Secondary (5-8) & $.84(0.17-4.19)$ & $1.55 \%$ \\
\hline High School (9-11) & $.27(0.04-1.79)$ & $4.54 \%$ \\
\hline Approved years & $.90(0.68-1.20)$ & $.73 \%$ \\
\hline Socioeconomic status (strata) & $.49(0.04-5.11)$ & $.63 \%$ \\
\hline Behavioural symptoms & $.10(0.02-0.50)$ & $30.65 \%$ \\
\hline Intelligence quotient (IQ) & $.97(0.93-1.01)$ & $2.93 \%$ \\
\hline Vocabulary & $.97(0.93-1.01)$ & $2.10 \%$ \\
\hline Matrices & $.97(0.94-1.01)$ & $2.38 \%$ \\
\hline $\mathrm{IQ}>90$ points & $3.46(0.96-12.39)$ & $6.35 \%$ \\
\hline Reading the Mind in the Eyes test & $1.44(1.15-1.80)$ & $34.93 \%$ \\
\hline Cognitive empathy & $1.34(1.07-1.67)$ & $14.04 \%$ \\
\hline Perspective taking & $1.43(1.15-1.78)$ & $28.64 \%$ \\
\hline Fantasy & $1.03(0.89-1.18)$ & $.27 \%$ \\
\hline Emotional empathy & $1.60(1.12-2.14)$ & $34.27 \%$ \\
\hline Empathic concern & $1.44(1.15-1.80)$ & $30.14 \%$ \\
\hline Personal distress & $1.33(1.10-1.61)$ & $21.01 \%$ \\
\hline
\end{tabular}


Table 3 Multivariate model for association with female gender in adolescents with conduct disorder.

\begin{tabular}{lcccc}
\hline \multicolumn{1}{c}{ Variable } & Odds Ratio & Error & $Z$ value & $p$ value \\
\hline Reading the Mind in the Eyes test & $1.74(1.15-2.63)$ & .3669 & 2.63 & .009 \\
Emotional empathy & $2.15(1.12-4.11)$ & .7108 & 2.33 \\
Constant & $1.5 e^{-12}\left(3.1 e^{-21}-0.0\right)$ & $1.5 e^{-12}$ & -2.67 & .008 \\
\hline
\end{tabular}

Assumptions of the model were met as the dependent variable was not linear (the inclusion of independent qualitative variables was finally avoided) and the no-zero cells rule was followed by the software default procedures. Besides, there was an appropriate specification in linktest (square estimation, $p=.181$ ), and adjustment with Pearson's chi-squared statistics of $44.81(p=.241)$ and Hosmer-Lemeshow of $7.74(p=.459)$ were identified in the evaluation of the model. Finally, residuals prediction identified that $97.82 \%$ of the sample had values between -2 and 2 . The remaining individual had a residual of 6.31. Thus, we considered analysing the specific characteristics of this female subject as a possible influential case. When running the model without this participant, its pseudo $\mathrm{R}^{2}$ increases to $83.51 \%$, maintaining a correct specification and goodness of fit.

\section{DISCUSSION}

The purpose of this study was to investigate gender differences in theory of mind and empathy abilities in a sample of adolescents with conduct disorder. Our results demonstrated significant differences between both genders in abilities regarding empathy, theory of mind and behavioural symptoms. Women showed consistently higher scores in multiple empathy and theory of mind variables, and less behavioural symptoms. Data indicate that the most significant differences between both genders were established by emotional empathy subscales (empathic concern and personal distress). Some previous researches support these results. At the same time, they reveal multiple implications of empathy in adolescent's social functioning, including antisocial behaviours (Crocetti et al., 2016; Graaff et al., 2015).

Especially, there is evidence showing that emotional empathy plays a main role in antisocial behaviours expression during childhood and adolescence, both in men and women (Batanova \& Loukas, 2014). Some longitudinal studies ratify negative systematic associations between levels of emotional empathy and levels of delinquency and aggressive behaviour in adolescents with conduct disorder. This demonstrates that high levels of empathic concern are predictive for the decrease of antisocial behaviours (Batanova \& Loukas, 2011). Besides, these negative associations have been confirmed with bullying, especially in women, who prefer to use relational aggressions (Caravita, Blasio \& Salmivalli, 2009).

This last statement is consistent with our results and suggests the influence of gender when it come to the type and seriousness of disruptive behaviours. Apparently, in women there exists an inverse connection between emotional empathy abilities and the number of behavioural symptoms, in contrast to men. This is due to the importance of affective processing in women which helps them to respond with a higher empathic concern for others. They also present feelings of concern for the negative consequences their actions have on other people.

Unlike emotional empathy, cognitive empathy has been associated with perspective taking processes, which doesn't mitigate significantly transgressive behaviours (Broidy et al., 2003; Graaff et al., 2014). Indeed, there is evidence upholding positive associations between perspective taking and relational aggressions depending on gender, even after controlling these associations with empathic concern scores (Batanova \& Loukas, 2011).

Moreover, in the context of aggressive behaviour, the ability to assume somebody else's point of view has been considered as an indication of social intelligence, making possible the implementation of strategies to victimize secretly, in turn, reducing the probabilities of being caught (Bjorkqvist, Osterman, \& Kankiainen, 2000; Gini, 2006; Sutton, Smith, \& Swettenham, 1999; Smith, 2017). Our results support the evidence of the regulatory and inhibiting role of emotional empathy, and the moderating effect of the gender variable over the type of aggressions (physical/ relational) and the number of behavioural symptoms (Ackermann et al., 2019; Crapanzano, Frick, \& Terranova, 2009; Holl et al., 2018; Lovett \& Sheffield, 2007).

Complementarily, some studies have explored the relationship between theory of mind and aggressive behaviour in children and adolescents. Recent evidence regarding these relationships indicates mixed results (Crick \& Dodge, 1994; Gómez-Garibello, \& Talwar, 2015; Holl et al., 2018; Hughes \& Devine, 2015; Song, Volling, Lane, \& Wellman, 2016; Sutton et al., 1999). Some authors support a vision of deficiencies in theory of mind and their mutual link with biases in social information processing, which leads to the appearance of aggressive behaviours (Crick \& Dodge, 1994). In contrast, other authors considered a vision where abilities in theory of mind are positively related with aggressive behaviours (Smith, 2017; Sutton et al., 1999). Although the results of this research suggest differences in behavioural symptoms in both genders, it's not possible to support or reject any of these perspectives since the sample used in this study showed deficiencies both in empathy and theory of mind in comparison with values reported elsewhere for the common population. We can suggest the existence of a mutual link between emotional empathy and theory of mind (perspective taking) as attenuators of behavioural symptoms, especially in women. Nevertheless, it is necessary to expand research in order to establish the effect of abilities or deficiencies in theory of mind over conduct disorder.

Discoveries of this study should be interpreted in light of some limitations. First, both the sample size and the selection of participants impede the extrapolation of results to the general population of adolescents with conduct disorder. However, our results seem to be similar to 
those of studies with bigger samples and longitudinal designs (Batanova \& Loukas, 2014; Holl et al., 2018; Kokkinos et al., 2016). Second, the evaluation of empathy and its dimensions (cognitive and emotional) was made through the Interpersonal Reactivity Index (IRI, Davis, 1980). The IRI is a questionnaire widely used in current literature about empathy, and it offers suitable validity and reliability levels. Nevertheless, it might have produced biased responses because of its self-report nature, potentially modifying the associations indicated in this study.

Third, given that the differences in types of aggressions between men and women were not established, we could not make inferences far from empirical evidence regarding the differences in the number of symptoms and its correlation with empathy. Even though, there is a general agreement, both in psychopathologic and clinical research areas, when establishing the differences in types of aggression depending on gender (American Psychiatric Association, 2013).

In summary, the results showed that the most significant associated factors with the female gender were their scores in Reading the Mind in the Eyes test and emotional empathy. The interaction between those factors might be an attenuator component of behavioural symptoms. Therefore, this could help to clinically distinguish disruptive behavioural patterns of conduct disorder between men and women. For future studies it is recommended to consider other variables that could be potential moderators of gender differences in conduct disorder. For instance, the presence or absence of callous unemotional traits, producing a series of emotional and affective characteristics linked to deficiencies in emotion recognition, lack of empathy and carelessness for the feelings of others. We suggest complementing the information derived from self-reports with parents or teachers' reports. What's more, measurements with execution, experimental or psychophysiological tasks can also be employed.

\section{REFERENCES}

Ackermann, K., Kirchner, M., Bernhard, A., Martinelli, A., Anomitri, C., Baker, R.,...Freitag, C. M. (2019). Relational aggression in adolescents with conduct disorder: Sex differences and behavioural correlates. Journal of Abnormal Child Psychology, 1-13. https://doi.org/10.1007/s10802-019-00541-6

American Psychiatric Association (2013). Diagnostic and Statistical Manual of Mental Disorders (DSM-V), Washington, D.C, USA: American Psychiatric Association.

Arango Tobón, O. E., Olivera-La Rosa, A., Restrepo Tamayo, V., \& Puerta Lopera, I. C. (2018). Empathic abilities and theory of mind in female adolescents with conduct disorder. Brazilian Journal of Psychiatry, 40(1), 78-82. https://doi.org/10.1590/1516-44462016-2092

Arango Tobón, O. E., Montoya, Z. P., Puerta, L. I., \& Sánchez, D. J. (2014). Teoría de la mente y empatía como predictores de conductas disociales en la adolescencia. Escritos de Psicología, 7(1), 20-30. https://doi.org/10.5231/psy.writ.2013.2810

Baker, K. (2009). Conduct disorder in children and adolescents. Paediatrics and Child Health, 19(2), 73-78. https://doi. org/10.1016/j.paed.2012.09.007

Baron-Cohen, S., Wheelwright, S., Hill, J., Raste, Y., \& Plumb, I. (2001). The reading the mind in the eyes. Test revised version: A study with normal adults, and adults with Asperger syndrome or high-functioning autism. Journal of Child Psychology and Psychiatry and Allied Disciplines, 42(2), 241-251. https://doi. org/10.1017/S0021963001006643
Batanova, M. \& Loukas, A. (2011). Social anxiety and aggression in early adolescents. Journal of Youth and Adolescence, 40(11), 1534-1543. https://doi.org/10.1007/s10964-011-9634-x

Batanova M. \& Loukas A. (2014). Unique and interactive effects of empathy, family, and school factors on early adolescents' aggression. Journal of Youth and Adolescence, 43(11), 18901902. https://doi.org/10.1007/s10964-013-0051-1

Berkout, O. V., Young, J. N., \& Gross, A. M. (2011). Means girls and bad boys: Recent research on gender differences in conduct disorder. Aggression and Violent Behaviour, 16(6), 503-511. https://doi.org/10.1016/j.avb.2011.06.001

Bjorkqvist, K., Osterman, K., \& Kaukiainen, A. (2000). Social intelligence - empathy = aggression? Aggression and Violent Behaviour, 5(2), 191-200. https://doi.org/10.1016/S1359-1789(98)00029-9

Broidy, L., Cauffman, E., Espelage, D. L., Mazerolle, P., \& Piquero, A. (2003). Sex differences in empathy and its relation to juvenile offending. Violence and Victims, 18(5), 503-516. https://doi. org/10.1891/088667003780928143

Caravita, S., Blasio, P. D., \& Salmivalli, C. (2009). Unique and interactive effects of empathy and social status on involvement in bullying. Social Development, 18(1), 140-163. https://doi. org/10.1111/j.1467-9507.2008.00465.x

Crapanzano, A. M., Frick, P. J., \& Terranova, A. M. (2009). Patterns of physical and relational aggression in a school-based sample of boys and girls. Journal of Abnormal Child Psychology, 38(4), 433-445. https://doi.org/10.1007/s10802-009-9376-3

Crick, N. R., \& Dodge, K. A. (1994). A review and reformulation of social information-processing mechanisms in children's social adjustment. Psychological Bulletin, 115(1), 74-101. https://doi. org/10.1037/0033-2909.115.1.74

Crocetti, E., Van der Graaff, J., Moscatelli, S., Keijsers, L., Koot, H., Rubini, M.,... Branje, S. (2016). A longitudinal study on the effects of parental monitoring on adolescent antisocial behaviours: The moderating role of adolescent empathy. Frontiers in Psychology, 7. https://doi.org/10.3389/fpsyg.2016.01726

Davis, M. H. (1980). A multidimensional approach to individual differences in empathy. JSAS Catalog of Selected Documents in Psychology, 10, 85.

Davis, M. H. (1983). Measuring individual differences in empathy: Evidence for a multidimensional approach. Journal of Personality and Social Psychology, 44(1), 113-126. https://doi. org/10.1037/0022-3514.44.1.113

Davis, M. H. (1996). Empathy: A Social Psychological Approach. Madison, USA: Westview Press.

Deschamps, P. K., Scutter, D. J., Renemans, J. L., \& Matthys, W. (2014). Empathy and pro-social behaviour in response to sadness and distress in 6 to 7 years old diagnoses with disruptive behaviour disorder and attention-deficit hyperactivity disorder. European Child \& Adolescent Psychiatry, 24(1), 105-113. https:// doi.org/10.1007/s00787-014-0535-x

Eisenberg, N., \& Eggum, N. D. (2009). Empathic responding: Sympathy and personal distress. The Social Neuroscience of Empathy, 7183. https://doi.org/10.7551/mitpress/9780262012973.003.0007

Eisenberg, N., Fabes, R. A., \& Spinrad, T. L. (2006). Handbook of Child Psychology, Volume 3: Social, Emotional, and Personality Development. New Jersey, USA: Wiley.

Ellis, P. L. (1982). Empathy: A factor in antisocial behaviour. Journal of Abnormal Child Psychology, 10(1), 123-133. https://doi. org/10.1007/BF00915957

Fairchild, G. \& Smaragdi, A. (2018). The neurobiology of offending behaviour in adolescence. In A. R. Beech, A. J. Carter, R. E. Mann \& P. Rotshtein, (Eds.), The Wiley Blackwell Handbook of Forensic Neuroscience (pp. 421-453). https://doi. org/10.1002/9781118650868.ch16

Fairchild, G., Stobbe, Y., Van Goozen, S., Calder, A., \& Goodyer, I. (2010). Facial expression recognition, fear conditioning, and startle modulation in female subjects with conduct disorder. Biological Psychiatry, 68(3), 272-279. https://doi.org/10.1016/j. biopsych.2010.02.019 
Gini G. (2006). Social cognition and moral cognition in bullying: What's wrong? Aggressive Behaviour, 32(6), 528-539. https:// doi.org/10.1002/ab.20153

Gomez-Garibello, C., \& Talwar, V. (2015). Can you read my mind? Age as a moderator in the relationship between theory of mind and relational aggression. International Journal of Behavioural Development, 39(6), 552-559. https://doi. org/10.1177/0165025415580805

Graaff J. V., Meeus W., de Wied M., Boxtel A. V., Lier P. A. C., Koot H. M., \& Branje, S. (2015). Motor, affective and cognitive empathy in adolescence: Interrelations between facial electromyography and self-reported trait and state measures. Cognition and Emotion, 30(4), 745-761. https://doi.org/10.1080/02699931 .2015 .1027665

Graaff, J. V., Branje, S. J., Wied, M. A., Hawk, S. T., Lier, P. A., \& Meeus, W. H. (2014). Perspective taking and empathic concern in adolescence: Gender differences in developmental changes. Developmental Psychology, 50(3), 881-888. https://doi. org/10.1037/a0034325

Holl, A. K., Kirsch, F., Rohlf, H., Krahé, B., \& Elsner, B. (2018). Longitudinal reciprocity between theory of mind and aggression in middle childhood. International Journal of Behavioural Development, 42(2), 257-266. https://doi.org/10.1177/0165025417727875

Hughes, C., \& Devine, R. T. (2015). Individual differences in theory of mind from preschool to adolescence: Achievements and directions. Child Development Perspectives, 9(3), 149-153. https://doi. org/10.1111/cdep.12124

Ibanez, A., Huepe, D., Gempp, R., Gutiérrez, V., \& Rivera-Rei, A. (2013). Empathy, sex and fluid intelligence as predictors of theory of mind. Personality and Individual Differences, 54(5), 616621. https://doi.org/10.1016/j.paid.2012.11.022

Kaufman, A. S., \& Kaufman, N. L. (1997). K-BIT. Test Breve de inteligencia de Kaufman. Adaptación al español de Agustín Cordero e Isabel Calonge. Madrid, España: TEA Ediciones.

Keenan, K., Wroblewski, K., Hipwell, A., Loeber, R., \& Stouthamer-Loeber, M. (2010). Age of onset, symptom threshold, and the expansion of the nosology of conduct disorder for girls. Journal of Abnormal Psychology, 119(4), 689-698. https://doi. org/10.1037/a0019346

Kokkinos, C. M., Voulgaridou, I., Mandrali, M., \& Parousidou, C. (2016). Interactive links between relational aggression, theory of mind, and moral disengagement among early adolescents. Psychology in the Schools, 53(3), 253-269. https://doi. org/10.1002/pits.21902

Lovett, B. J., \& Sheffield, R. A. (2007). Affective empathy deficits in aggressive children and adolescents: A critical review. Clinical Psychology Review, 27(1), 1-13. https://doi.org/10.1016/j. cpr.2006.03.003

Marshall, L. E., \& Marshall, W. L. (2011). Empathy and antisocial behaviour. Journal of Forensic Psychiatry and Psychology, 22(5), 742-759. https://doi.org/10.1080/14789949.2011.617544

Mceachern, A. D., y Snyder, J. (2012). Gender differences in predicting antisocial behaviours: Developmental consequences of physical and relational aggression. Journal Abnormal Child Psychology, 40(4), 501-512. https://doi.org/10.1007/s10802-0119589-0

Olweus, D. (1999). Sweden. In Smith, P. K., Morita, Y., Junger-Tas, J., Olweus, D., Catalano, R., \& Slee, P. (Eds.), The nature of school bullying: A cross-national perspective (7-27). New York, USA: Routledge.

Peets, K., Hodges, E. V. \& Salmivalli, C. (2010). Actualization of social cognitions into aggressive behaviour toward disliked targets. Social Development, 20(2), 233-250. https://doi. org/10.1111/j.1467-9507.2010.00581.x
Pérez Albéniz, A., Paúl, J., Etxeberría, J., Montes, M., \& Torres, E. (2003). Adaptación de Interpersonal Reactivity Index (IRI) al español. Psicothema, 15(2), 267-272.

Premack, D., \& Woodruff, G. (1978). Does the chimpanzee have a theory of mind? Behavioural and Brain Sciences, 1(4), 515-526. https://doi.org/10.1017/S0140525X00076512

Rueda, P., Cabello, R., \& Fernández-Berrocal, P. (2013). Preliminary validation of Spanish "Eyes Test-Child Version." Ansiedad y Estrés, 19(2-3), 173-184.

Sharp, C. (2000). Biased minds: Theory of mind and emotional-behaviour disorders of middle childhood (Unpublished manuscript) University of Cambridge, Cambridge, UK.

Sharp, C. (2006). Mentalizing problems in childhood disorders. In J. G. Allen \& P. Fonagy (Eds.), Handbook of mentalization-based treatments (pp. 101-121). Chichester, UK: Wiley.

Sharp, C. (2008). Theory of mind and conduct problems in children: Deficits in reading the "emotion of the eye". Cognition and Emotion, 22(6), 1149-1158. https://doi.org/10.1080/ 02699930701667586

Sharp, C., Croudace, T. J., \& Goodyer, I. M. (2007). Biased mentalizing in children aged seven to 11: Latent class confirmation of response styles to social scenarios and associations with psychopathology. Social Development, 16(1), 181-202. https://doi. org/10.1111/j.1467-9507.2007.00378.x

Sheehan, D. V., Lecrubier, Y., Harnett-Sheehan, K., Janavs, J., Weiller, E., Dunbar, G. C., Keskiner, A., Schinka, J., Knapp, E., \& Sheehan, M. F. (1997). Reliability and validity of the Mini International Neuropsychiatric Interview (MINI): According of the SCID-P. European Psychiatry, 12(5), 232-241. https://doi. org/10.1016/S0924-9338(97)83297-X

Sheehan, D., Shytle, D., Milo, K., Lecrubier, Y. \& Jergueta, T. (2006). Mini International Neuropsychiatric Interview. For children and adolescents (M.I.N.I. - KID). Mini Entrevista Neuropsiquiátrica Internacional para niños y adolescentes M.I.N.I. - $(N-A)$. Adaptación al español colombiano. Pineda, D. Medellín: Universidad de San Buenaventura - Universidad de Antioquia.

Smith, P. K. (2017). Bullying and theory of mind: A review. Current Psychiatry Reviews, 13(2), 1-6. https://doi.org/10.2174/157340 0513666170502123214

Song, J. H., Volling, B. L., Lane, J. D., \& Wellman, H. M. (2016). Aggression, sibling antagonism, and theory of mind during the first year of siblinghood: A developmental cascade model. Child Development, 87(4), 1250-1263. https://doi.org/10.1111/ cdev. 12530

Stavrinides, P., Georgiou, S., \& Theofanous, V. (2010). Bullying and empathy: A short-term longitudinal investigation. Educational Psychology, 30(7), 793-802. https://doi.org/10.1080/01443410. 2010.506004

Sutton, J., Smith, P. K., \& Swettenham, J. (1999). Bullying and 'theory of mind': A critique of the 'social abilities deficit' approach to anti-social behaviour. Social Development, 8(1), 117-127. https://doi.org/10.1111/1467-9507.00083

Walker, S. (2005). Gender differences in the relationship between young children's peer-related social competence and individual differences in theory of mind. The Journal of Genetic Psychology, 166 (3), 297-312. https://doi.org/10.3200/GNTP.166.3.297-312

Warnell, K., \& Redcay, E. (2019). Minimal coherence among varied theory of mind measures in childhood and adulthood. Cognition 191, 103997. https://doi.org/10.1016/j.cognition.2019.06.009 